M.A. Shaheen, A.S.J. Foster, L.S. Cunningham, S. Afshan. (2020) A numerical investigation into stripping failure of bolt assemblies at elevated temperatures. Structures. 27, 1458-1466.

\title{
A numerical investigation into stripping failure of bolt assemblies at elevated temperatures
}

\author{
Mohamed A. Shaheen ${ }^{\mathrm{a}}$, Andrew S. J. Foster, ${ }^{\mathrm{a}, *}$, Lee S. Cunningham ${ }^{\mathrm{a}}$, Sheida Afshan ${ }^{\mathrm{b}}$ \\ ${ }^{a}$ School of Mechanical, Aerospace and Civil Engineering, The University of Manchester, Manchester, UK \\ ${ }^{b}$ Department of Civil \& Environmental Engineering, The University of Southampton, Southampton, UK
}

\begin{abstract}
A detailed finite element (FE) study is presented investigating the factors affecting the failure modes of high strength and stainless steel bolt assemblies under tensile force at ambient and elevated temperatures. Axisymmetric FE models incorporating key behavioural aspects including surface interaction and damage modelling of steel at elevated temperatures were developed. In practice, stripping failure is generally undesired because it results in premature failure of the bolt which can deteriorate rotational capacity of connections and hence compromise the robustness of steel frames. Yet, stripping failure has not been previously investigated in the open literature. In this study, the examined stainless steel bolt assemblies displayed an outstanding ductile response even when stripping failure was observed. Parameters that can govern the failure modes of bolt assemblies at elevated temperatures include the thread length in the grip $\left(L_{t}\right)$, and the relative strength and friction between the mating threads. At ambient temperature, stripping was observed at certain $L_{t}$ lengths depending on the nut dimension deviation from the basic profile. The $L_{t}$ stripping failure threshold reduces with temperature for high strength bolt assemblies while the value fluctuates without a discernible pattern for stainless steel types. Increasing the relative strength and friction coefficient can reduce the $L_{t}$ length threshold, with the former having the greatest influence.
\end{abstract}

\footnotetext{
${ }^{*}$ Corresponding author

Email addresses: m.shaheen@manchester.ac.uk (Mohamed A. Shaheen), andrew.s.j.foster@manchester.ac.uk (Andrew S. J. Foster)
} 
It was also found that larger bolt sizes are more vulnerable to thread stripping failure.

Keywords: High strength bolt, Stainless steel bolt, Stripping failure, Necking failure. 


\section{Introduction}

Bolted connections are ubiquitous in steel frame construction. The characteristic behaviour of bolt assemblies, consisting of the bolt itself and the nut, has a major effect on the ductility and response of the overall structural system. Ultimately, there are primarily two failure modes associated with steel bolt assemblies under tensile force [1]: necking failure and stripping failure. The former is a ductile failure involving substantial plastic deformation in the bolt threads. Stripping failure is a shear failure of the engaged threads in either the nut or bolt. Both failure modes are illustrated in Fig. 1. Experimental work carried out on moment resisting steel beam-column connections during fire events showed that bolt stripping drastically deteriorates the rotational capacity of connections and accordingly the robustness of steel frames $[2-4]$.

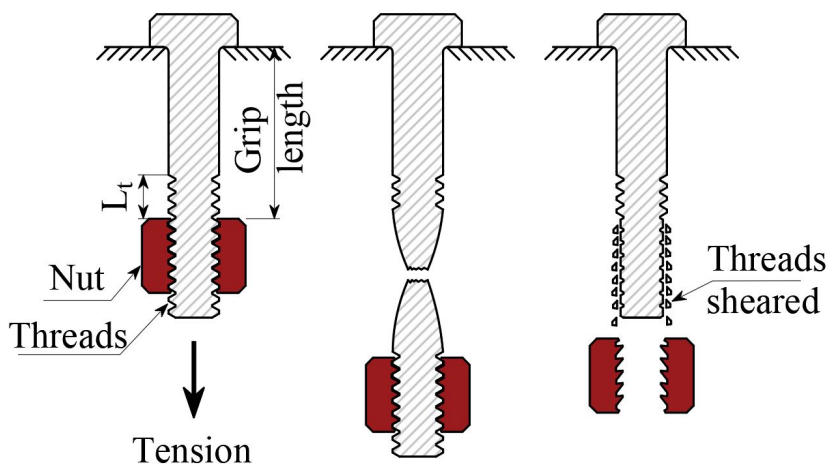

(a)

(b)

(c)

Figure 1: Bolt failures under tensile force: (a) terminology; (b) necking failure (c) stripping failure.

Experimental tests conducted on steel bolt assemblies concluded that stripping failure reduces the bolt capacity [5-7] and severely deteriorates its ductility [8]; using a close-fitting nut and bolt is necessary to achieve the full capacity of high strength bolts [5]. Hu et al. [6] carried out tests on M20 grade 8.8 bolts with different nut property classes ( 8 and 10) and concluded that nuts of one property class higher (e.g. using bolt Gr 8.8 with nut property 
class 10) is more likely to cause failure with ductile necking. There are numerous parameters that affect the ductility and failure modes of bolt assemblies during fire events such as relative strength and friction between the mating threads, fitting between threads and the number of threads in the grip. These and other parameters have been extensively studied at ambient temperature and well documented in the international regulations $[9,10]$. However, these parameters have not been re-evaluated at elevated temperatures.

Alexander [11] has theoretically discussed the effect of thread length in the grip, $L_{t}$, (see Fig. 1a) on the failure mode of bolt assemblies, but there are no publications in the open literature that experimentally investigate how the $L_{t}$ affects the failure mode of bolt assemblies [8]. It was concluded that stripping failure can be prevented at ambient temperature when the $L_{t}$ is larger than $17 \mathrm{~mm}$ for M16 Gr 8.8 bolts mated with nut property class 8 and tolerance class $6 \mathrm{~g} 6 \mathrm{H}$. It has been documented that increasing the nut strength does not prevent stripping failure, however, it enhances the failure displacement [8]. Chen et al. [12] numerically investigated the effect of friction coefficient $\mu$ on the load distribution on threads at ambient temperature concluding that the helical effect of the threads does not influence the load distribution. Hu et al. [7] numerically investigate the effect of nut tolerance class on the failure mode of bolt assemblies at ambient temperature concluding that a loose tolerance class results in stripping failure.

At elevated temperatures the picture is substantially less complete and generally lacking in consistency. Despite the available coupled thermal modelling capabilities of modern finite element (FE) codes, only one publication was reported for FE analysis of bolts at elevated temperatures [13], which discusses high strength bolt strength reduction factors. An elastoplastic material constitutive law was considered, however, the damage modelling and failure modes of the bolt assemblies were overlooked. 
The current paper presents a numerical study that investigates the parameters affecting the ductility and failure modes of structural bolt assemblies at elevated temperatures. In keeping with common practice, high strength Gr 8.8 [14] was considered in this study. Stainless steel bolts of grade A2-80[15], which have an equivalent strength of Gr 8.8, were also considered to provide comparison of behaviour at elevated temperature. The FE models were developed using ABAQUS [16] and were carefully validated against experimental test data in the literature, focusing in particular on capturing the post beak behaviour and local failure modes (stripping and necking). The bolt material was modelled considering damage initiation and evolution, which was calibrated against coupon tests found in the literature. Heat transfer analysis and thermal expansion were not considered in this study.

\section{FE modelling approach}

\subsection{Geometry and boundary conditions of bolt assemblies and element types}

The overall dimensions of the bolts (bolt head, shank and thread length) and nuts (wall thickness and height) were selected based on BS EN 4014 [17] and BS EN ISO 4032 [18], respectively. An axisymmetric model was exploited in order to reduce the computational time. Despite the axisymmetric model being unable to simulate the lead angle due to the helical effect, the results reported by $[8,12,19]$ showed that it has a minor influence on the bolt assembly's response.

As previously stated the behaviour of the bolt assembly is affected by various geometrical parameters particularly the fitting between mating threads, which is determined by the tolerance class, combining tolerance position and tolerance grade. The tolerance position is the basic clearance between the external (bolt) and internal (nut) threads and is identified 
based on BS EN 965-1 [20]. Tables 1 and 2 summarise the basic dimensions and upper and lower dimension deviations for tolerance class $6 \mathrm{~g} 6 \mathrm{H}$ [20], which is considered in this study (see Fig. 2 for the definition of nomenclature used in the tables).
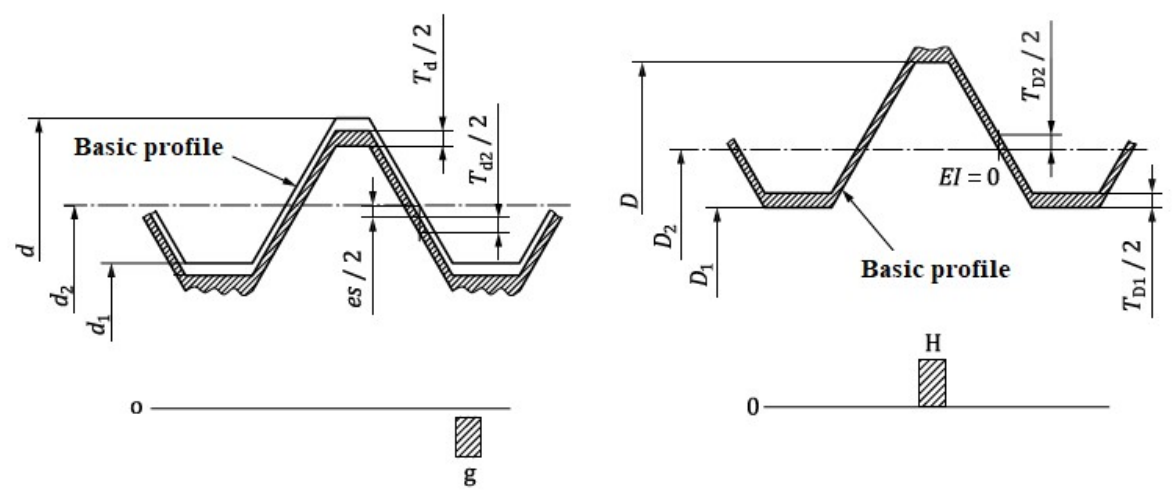

Figure 2: Tolerance position a) position $\mathrm{g}$ b) position $\mathrm{H}$ Based on [20].

To account for the nut dilation, the upper surface of the nut was assigned to have fixed boundary conditions in the $y$-direction (parallel to the bolt axis) and was free to move in the $x$-direction (perpendicular to the bolt axis). The load was applied to the bottom surface of the bolt head parallel to the $y$-direction. A displacement control approach was adopted as it is numerically more stable and it is capable of capturing the post peak behaviour. Fig. 3 illustrates the mesh topology and boundary conditions of the bolt assemblies. The material damage parameters are mesh-dependent $[21,22]$, thus, the same mesh size and type as described in section 2.2 were followed herein. A 4-node bilinear axisymmetric quadrilateral, reduced integration element type CAX4R was assigned to the bolt and the nut. A very fine mesh of $0.18 \mathrm{~mm}$ was considered at locations of high stress concentrations (boundary conditions and engaged threads) while $1 \mathrm{~mm}$ was used elsewhere. 


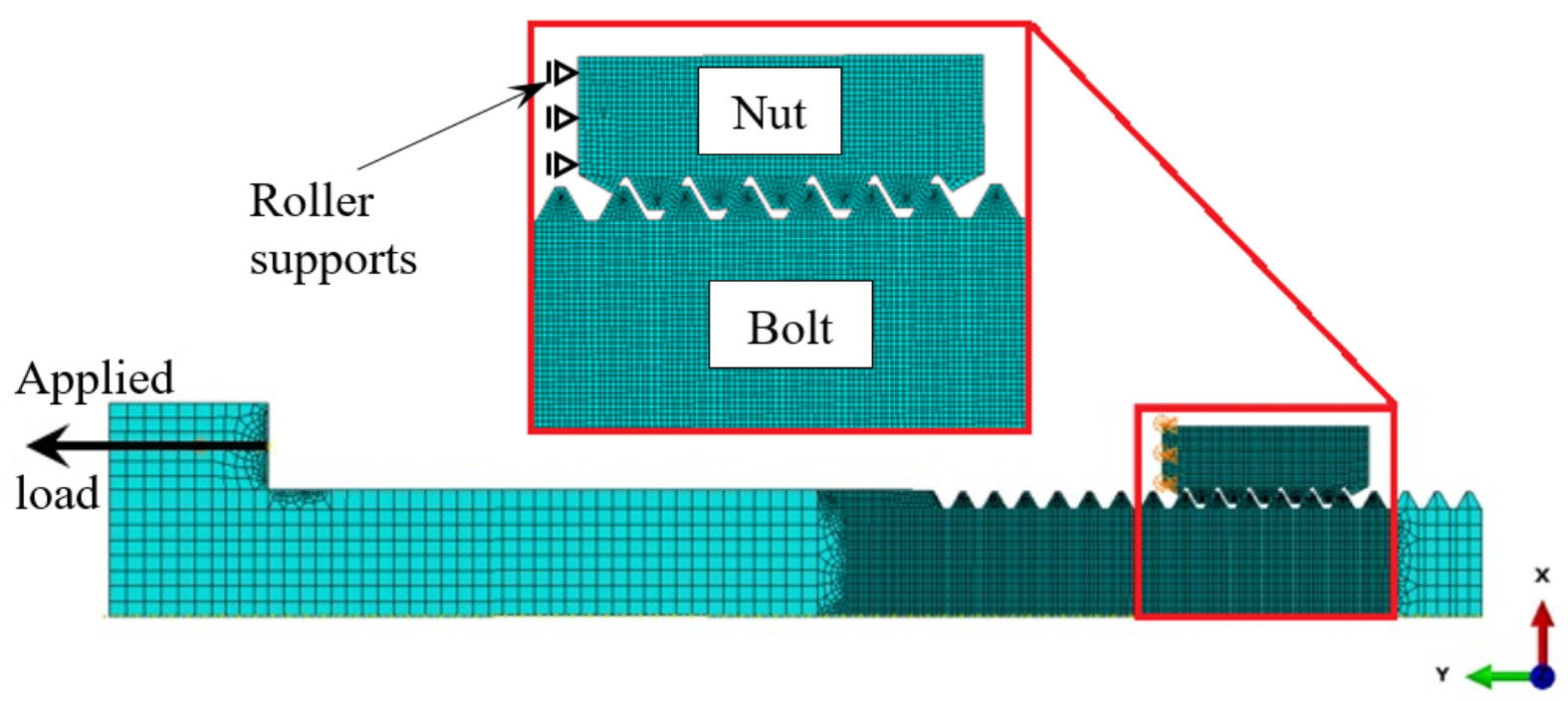

Figure 3: Boundary conditions and mesh topology.

Table 1: Dimension details of bolt threads based on BS EN 965-1 [20]

\begin{tabular}{|c|c|c|c|c|c|c|}
\hline \multicolumn{3}{|c|}{$\begin{array}{l}\text { Basic dimensions for } \\
\text { M16 (pitch =2 mm) }\end{array}$} & \multicolumn{4}{|c|}{$\begin{array}{l}\text { Dimension deviation of } \\
\text { tolerance class } 6 \mathrm{~g}\end{array}$} \\
\hline $\mathrm{d}(\mathrm{mm})$ & $\mathrm{d} 1(\mathrm{~mm})$ & $\mathrm{d} 2(\mathrm{~mm})$ & Deviation & $\mathrm{d}(\mathrm{mm})$ & $\mathrm{d} 1$ (mm) & $\mathrm{d} 2(\mathrm{~mm})$ \\
\hline \multirow{2}{*}{16} & \multirow{2}{*}{13.835} & \multirow{2}{*}{14.701} & Upper & -0.318 & -0.327 & -0.198 \\
\hline & & & Lower & -0.038 & -0.327 & -0.038 \\
\hline
\end{tabular}

\subsection{Material parameter identification and validation}

Isotropic metal plasticity was used to define the material model parameters for high strength and stainless steel bolts at elevated temperature. Progressive damage models featured in ABAQUS/Standard [16] were also used to account for failure modes and element removal. The damage initiation and evolution parameters defined in this article followed the description provided by Pavlovic et al. [22] for bolts at ambient temperature. However, the damage

Table 2: Dimension details of nut threads based on BS EN 965-1 [20]

\begin{tabular}{|l|l|l|l|l|l|l|}
\hline $\begin{array}{l}\text { Basic dimensions for } \\
\text { M16 (pitch = 2 mm) }\end{array}$ & \multicolumn{4}{l|}{$\begin{array}{l}\text { Dimension deviation of } \\
\text { tolerance class 6H }\end{array}$} \\
\hline $\mathrm{D}(\mathrm{mm})$ & $\mathrm{D} 1(\mathrm{~mm})$ & $\mathrm{D} 2(\mathrm{~mm})$ & Deviation & $\mathrm{D}(\mathrm{mm})$ & $\mathrm{D} 1(\mathrm{~mm})$ & $\mathrm{D} 2(\mathrm{~mm})$ \\
\hline \multirow{2}{*}{16} & \multirow{2}{*}{13.835} & \multirow{2}{*}{14.701} & Upper & 0.0 & 0.375 & 0.212 \\
\cline { 4 - 7 } & & Lower & 0.0 & 0.0 & 0.0 \\
\hline
\end{tabular}


parameters were re-evaluated to suit the elevated temperature behaviour and summarised in Table 3 and 4 for high strength and stainless steel, respectively.

Table 3: Damage parameters for high strength bolt at elevated temperatures.

\begin{tabular}{|c|c|c|c|c|c|c|c|c|}
\hline \multirow{2}{*}{ Temp. ${ }^{\circ} \mathbf{C}$} & \multicolumn{2}{|c|}{ Damage initiation } & Element type & \multicolumn{2}{|c|}{ Element size } & \multicolumn{2}{|c|}{ Localization } \\
\cline { 2 - 8 } & $\varepsilon_{n, p l}$ & $\alpha_{D}$ & Type & $\lambda_{E}$ & $L_{E}(\mathbf{m m})$ & $\lambda_{s}$ & $L_{l o c}$ & $\alpha_{L}$ \\
\hline $20-300$ & 0.024509 & 1.3 & CAX4R & 4 & 0.18 & 1 & 7.5 & 0.3 \\
\hline 400 & 0.020484 & 1.8 & CAX4R & 7 & 0.18 & 1 & 18 & 1 \\
\hline 500 & 0.00847 & 2 & CAX4R & 12 & 0.18 & 1 & 18 & 2 \\
\hline 600 & 0.005676 & 2 & CAX4R & 12 & 0.18 & 1 & 24 & 2 \\
\hline For definition of parameters see Pavlovic et al. [22]
\end{tabular}

Table 4: Damage parameters for stainless steel bolt at elevated temperatures.

\begin{tabular}{|c|c|c|c|c|c|c|c|c|}
\hline \multirow{2}{*}{ Temp. ${ }^{\circ} \mathbf{C}$} & \multicolumn{2}{|c|}{ Damage initiation } & \multicolumn{2}{c|}{ Element type } & \multicolumn{2}{c|}{ Element size } & \multicolumn{2}{c|}{ Localization } \\
\cline { 2 - 9 } & $\varepsilon_{n, p l}$ & $\alpha_{D}$ & Type & $\lambda_{E}$ & $L_{E}(\mathbf{m m})$ & $\lambda_{s}$ & $L_{l o c}$ & $\alpha_{L}$ \\
\hline 20 & 0.194059 & 1.5 & CAX4R & 7 & 0.18 & 1 & 3.6 & 0.3 \\
\hline 100 & 0.073815 & 1.2 & CAX4R & 4 & 0.18 & 1 & 3.6 & 0.3 \\
\hline 200 & 0.042838 & 1 & CAX4R & 3 & 0.18 & 1 & 3.6 & 0.3 \\
\hline 300 & 0.065842 & 1 & CAX4R & 7 & 0.18 & 1 & 3.6 & 0.3 \\
\hline 400 & 0.106881 & 1.5 & CAX4R & 5 & 0.18 & 1 & 3.6 & 0.3 \\
\hline 500 & 0.098803 & 1.1 & CAX4R & 4 & 0.18 & 1 & 5.4 & 0.3 \\
\hline 600 & 0.099514 & 1 & CAX4R & 6 & 0.18 & 1 & 7.2 & 0.3 \\
\hline For definition of parameters see Pavlovic et al. $[22]$ \\
\hline
\end{tabular}

Parameters for ductile damage initiation criterion and damage evolution laws were calculated based on tensile test coupons carried out by Kand [23] for high strength bolts grade A325 and Hu et al. [24] for stainless steel bolts grade A2-80. Despite the fact that high strength grade 8.8 was considered in the present study, the material was calibrated against an equivalent material grade A325 due to availability of the material tests at elevated temperature in the open literature. Studies carried out on high strength bolts at elevated temperature concluded that the material does not degrade with temperature until $300^{\circ} \mathrm{C}[5,6,25]$. Therefore, the FE results of the high strength bolts at ambient temperature were considered to represent the bolt behaviour up to $300^{\circ} \mathrm{C}$. Fig. $4 \mathrm{a}$ and Fig. $4 \mathrm{~b}$ compare the stress-strain curves of the 
experimental test and FE for the high strength and stainless steel coupon tests, respectively. There is an excellent agreement between the test data and the simulations up to the peak stress, with differences being less than 1\%. The FE model was also able to capture the post peak behaviour, as shown by the qualitative agreement between the experimental and numerical results in Figs. 4a and $4 \mathrm{~b}$

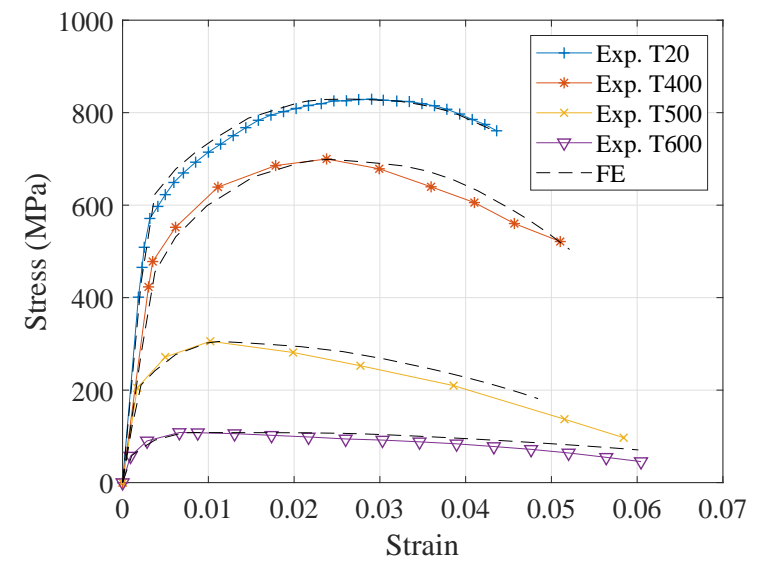

(a) High strength bolt assemblies.

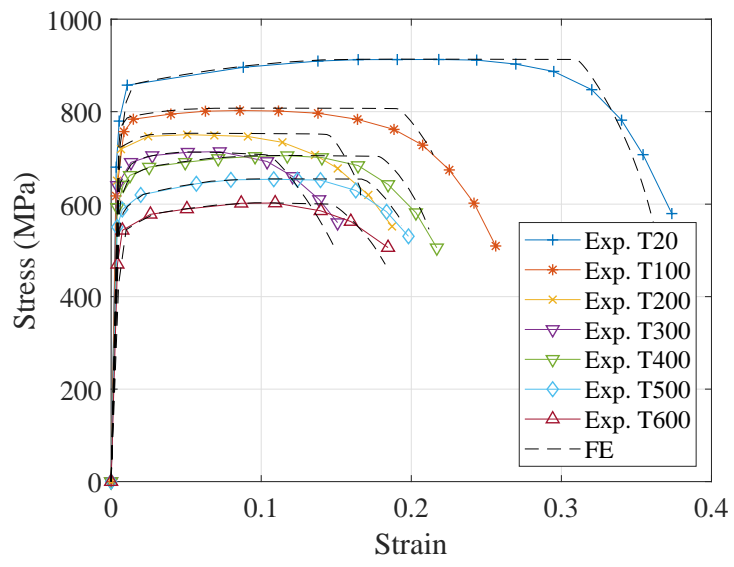

(b) Stainless steel bolt assemblies.

Figure 4: Comparison between numerical material modelling and experimental tests.

In order to calibrate the shear damage parameters, a FE model of a bolt under pure shear was analysed and the results was compared with the analytical model proposed by Sarraj [26]. Both the shear stress ratio and equivalent plastic strain at the onset of damage $\bar{\varepsilon}_{s}^{p l}$ are required to define the damage initiation criterion. Table 5 summarises the required $\bar{\varepsilon}_{s}^{p l}$ for high strength and stainless steel bolts at various temperatures. Although the analytical model proposed by Sarraj was calibrated against high strength bolts, it was used to predict the shear behaviour of stainless steel bolts due to the absence of load-displacement responses of stainless steel bolts under shear in the open literature. This assumption represents the worst case scenario as the stainless steel bolt possess significantly higher ductility than high strength types which require larger values of $\bar{\varepsilon}_{s}^{p l}$. In relation to this, a special 
Table 5: Equivalent plastic strain at the onset of shear damage $\bar{\varepsilon}_{s}^{p l}$ with temperature

\begin{tabular}{|c|c|c|c|c|c|c|c|}
\hline Temp. ${ }^{\circ} \mathrm{C}$ & 20 & 100 & 200 & 300 & 400 & 500 & 600 \\
\hline HS bolt & 0.75 & 0.75 & 0.75 & 0.75 & 1.4 & 1.3 & 0.8 \\
\hline SS bolt & 0.8 & 1.4 & 1.0 & 1.1 & 1.0 & 1.0 & 0.8 \\
\hline
\end{tabular}

investigation monitoring plastic strain at the damaged zone has been undertaken to check the consequences of this decision. The shear stress ratio was considered as 1.67 and 1.29 for high strength and stainless steel bolts respectively. The damage evolution parameters were defined using exponential softening with the exponential law parameter set to 0.7 and failure at a displacement of $0.2 \mathrm{~mm}$ as recommended by Pavlovic et al. [22].

The shear area of the nut thread is about $43 \%$ larger than the bolt thread area [11]. Therefore, the nut material was modelled using a bilinear stress-strain curve without considering material damage. For high strength nuts, the average Brinell hardness (HB) value of the range recommended by BS EN 898-2 [27] was selected for the analysis. The ultimate tensile stress (TS) of the nut was calculated as $\mathrm{TS}=3.45 \mathrm{xHB}[28]$. For stainless steel nuts, BS EN 3506-2 [29] provides the proof stress of the A2-80 nut as 800MPa, thus it was directly implemented.

\section{Validation of the bolt assembly models}

The failure modes observed by the FE model were validated against the experimental tests carried out by Grimsmo et al. [8] on seven partially-threaded galvanised M16 bolts with a different number of threads in the grip length $L_{t}$. Table 6 compares the results obtained from the FE model and the experimental test. The FE model can accurately predict the failure mode of the bolt assemblies at different nut locations albeit with slight mismatches for the stripping zone which may come from material modelling limitations and dimension differences between the tests and the simulated bolt assemblies. Fig. 5a depicts the load- 
displacement response of necking (when $L_{t}=8 x$ pitch distance) and stripping failure (when $L_{t}=7 x$ pitch distance) modes. Stripping failure results in a sudden drop in the load when the bolt capacity is reached while necking failure has a more ductile response.

Fig. 5b illustrates the damage location of the steel when the two failures were considered. The scalar stiffness degradation variable (SDEG) in ABAQUS was used to visualise the damaged parts. SDEG measures the residual stiffness of an element and takes a value from zero (undamaged material) to one (fully damaged material). The residual stiffness of an element is calculated based on the damage variable $D=1-\sigma / \bar{\sigma}$ where $\sigma / \bar{\sigma}$ is the ratio between the undamaged and damaged stress value of the material. The element is removed from the mesh if $D$ reaches unity, however, the lowest practical $D$ value considered during the analysis was 0.8 to avoid numerical instabilities. The plastic strain at the damaged parts was lower than the equivalent plastic strain at the onset of damage for the shear criterion $\bar{\varepsilon}_{s}^{p l}$, which reveals that damage was initiated and propagated following the ductile criterion.

Table 6: Failure mode comparison with Grimsmo tests.

\begin{tabular}{|c|c|c|}
\hline \multirow{2}{*}{ Failure mode } & \multicolumn{2}{|c|}{$L_{t}$ in terms of number of threads } \\
\cline { 2 - 3 } & Grimsmo tests & FE simulation \\
\hline Stripping zone & $<4$ & $<3$ \\
\hline Transition zone & $4-8$ & $3-8$ \\
\hline Necking zone & $\geq 8$ & $\geq 8$ \\
\hline
\end{tabular}




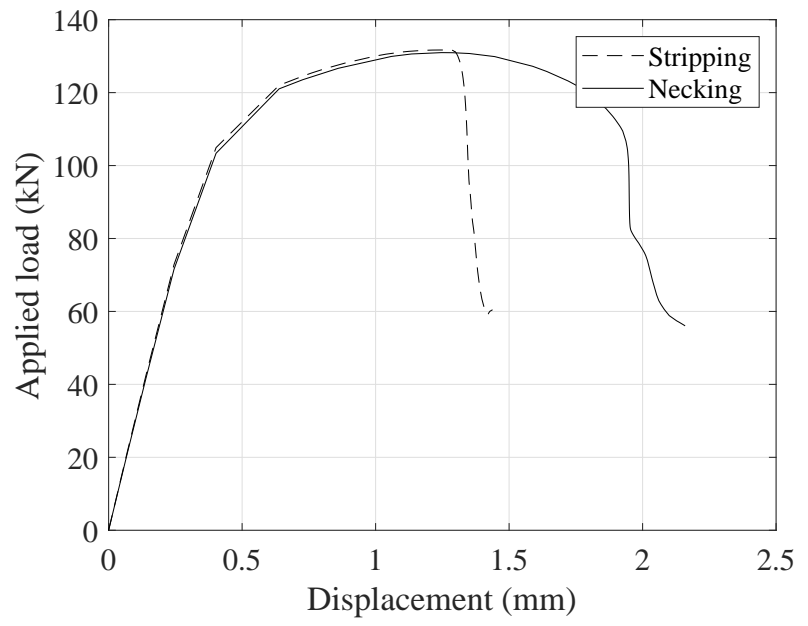

(a) Load-displacement curve.

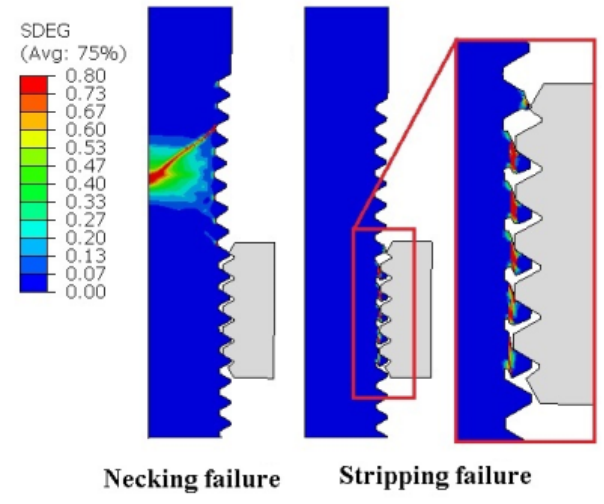

(b) Location of damage.

Figure 5: Behaviour of bolt assemblies with different failure modes.

\section{Parametric study}

This study investigates three major parameters that affect the failure modes of bolt assemblies at elevated temperature.

1. The first parameter is the effect of thread length in the grip $L_{t}$ on the failure modes of the bolt assemblies. Three different nut locations are possible (see Fig. 6): (i) the stripping zone (SZ) at which the stripping can occur regardless of the nut tolerance class or dimension deviation; (ii) the transition zone (TZ) at which stripping or necking are possible to occur depending on the nut dimension deviation; and (iii) the necking zone (NZ) at which the stripping failure is prevented. The primary objective of this parametric study is to ultimately define the $L_{t}$ boundaries between the three failure zones at different temperatures: $L_{t 1}$ is the minimum $L_{t}$ distance to define the $\mathrm{TZ}$ and $L_{t 2}$ is the minimum $L_{t}$ distance to define the NZ. Tolerance class $6 \mathrm{~g} 6 \mathrm{H}$ was considered in this study owing to its ubiquitous use in engineering practice $[17,18]$. Table 1 and 2 summarise the upper and lower deviation for bolts and nuts, respectively. The minimum deviation of the nut and the bolt was used within the SZ while the upper 
dimension deviation was used in the TZ and the NZ.

2. The second parameter is the relative strength between the mating threads. Experimental tests on bolt assemblies showed that the strength reduction factors are sensitive to the manufacturing process and chemical composition $[5,6,25]$. Bolts and nuts have different chemical compositions and pass through different heat treating processes which can eventually lead to uncertainties regarding the degradation rate of their mechanical properties with temperature. Thus, nuts with different Brinell hardness (HB) values mating with bolts that possessed similar material properties were analysed to provide a conservative scenario. The HB values were selected based on the recommended range proposed by BS EN ISO 898-2 [27] for high strength bolts and BS EN 3506-2 [29] for stainless steel bolts. The HB values recommended by BS EN ISO 898-2 [27] are 190-287 for nut property class 8 and 259-336 for nut property class 10. BS EN 3506-2 [29] provides only proof stress $\mathrm{F}_{\text {prof }}$ for austenitic steel nuts of grade A2-80 (no hardness ranges are provided), the minimum value recommended is $800 \mathrm{MPa}$. Table 7 summaries the nut strength and $\mathrm{HB}$ at ambient temperature; the nut strength at a specific temperature was calculated based on the same strength reduction factors as the bolts.

3. The third parameter is the friction $\mu$ between the mating threads, where $0.05 \leq \mu \leq$ 0.2 , depending upon the surface treatment used $[30,31]$. In this study, two different $\mu$ values were considered. In the absence of studies discussing the change in $\mu$ when zinc is melted a value of 0.05 was used at the temperature above melting point of the zinc $\left(425^{\circ} \mathrm{C}\right)$. The second $\mu$ value was 0.2 which represents friction at ambient temperature for high strength non-galvanised bolts at elevated temperature and stainless steel bolts at ambient and elevated temperature.

The above parameters were investigated across the temperature range of $20^{\circ} \mathrm{C}$ to $600^{\circ} \mathrm{C}$. The range of temperature was defined based on two considerations. Firstly, the availability of 
Table 7: Relative strength values used in the numerical models.

\begin{tabular}{|c|c|c|c|c|c|}
\hline FE model & Bolt type & $\begin{array}{l}\mathrm{F}_{\mathrm{u}} \text { at } 20^{\circ} \mathrm{C} \\
(\mathrm{MPa})\end{array}$ & $\mathrm{R}_{\mathrm{s}}$ & $\begin{array}{l}\text { Equivalent } \\
\text { property class }\end{array}$ & HB \\
\hline SS-Rs $=0.79$ & Stainless & 720 & 0.790 & NA & 208.70 \\
\hline SS-Rs $=0.965$ & Stainless & 880 & 0.965 & NA & 255.07 \\
\hline$* \mathrm{SS}-\mathrm{Rs}=1.096$ & Stainless & 1000 & 1.096 & NA & 289.86 \\
\hline $\mathrm{SS}-\mathrm{Rs}=1.2$ & Stainless & 1094 & 1.200 & NA & 317.10 \\
\hline $\mathrm{SS}-\mathrm{Rs}=1.4$ & Stainless & 1276 & 1.400 & NA & 369.85 \\
\hline HS-Rs $=0.79$ & High strength & 655 & 0.790 & 8 & 189.90 \\
\hline$* \mathrm{HS}-\mathrm{Rs}=0.965$ & High strength & 800 & 0.965 & 8 & 231.88 \\
\hline $\mathrm{HS}-\mathrm{Rs}=1.2$ & High strength & 1000 & 1.200 & 10 & 289.86 \\
\hline HS-Rs $=1.4$ & High strength & 1160 & 1.400 & 10 & 336.20 \\
\hline \multicolumn{6}{|c|}{$\begin{array}{l}\text { Where: } \mathrm{F}_{\mathrm{u}}=\text { ultimate strength, } \mathrm{R}_{\mathrm{s}}=\text { relative strength, } \mathrm{F}_{\mathrm{u}}=3.45 \mathrm{xHB} \text { and Yield } \\
\text { strength }=0.8 \mathrm{~F}_{\mathrm{u}}, \mathrm{NA}=\text { not applicable. } \\
\text { * Reference FE models. }\end{array}$} \\
\hline
\end{tabular}

material coupon test data: Kand [23] tested high strength bolts of grade A325 at elevated temperatures ranging between $20^{\circ} \mathrm{C}$ and $800^{\circ} \mathrm{C}$, however, the recorded stress-strain curve beyond $600^{\circ} \mathrm{C}$ experienced a severe distortion which may have resulted from a spurious displacement of the test rig. Thus it was decided to use the data up to $600^{\circ} \mathrm{C}$ only. Secondly, it is well documented that the bolt temperature is lower than the bottom flange of the host beam by roughly $150^{\circ} \mathrm{C}$ [32]. Thus, if the bolt is heated up to $600^{\circ} \mathrm{C}$, the flange temperature is expected to be $750^{\circ} \mathrm{C}$ which exceeds the limiting values of $540^{\circ} \mathrm{C}$ for columns and $620^{\circ} \mathrm{C}$ for beams [33].

Two types of bolts are available in engineering practice: partially-threaded and fully-threaded. The former type has a grip length below the bolt head free of threads while the latter has threads that run from just under the head all the way to the tip. Partially-threaded M16 bolts were primarily considered throughout this study, with minor consideration given to fully threaded bolts in section 10. The effect of bolt diameter on nut critical distances was also investigated in Section 9. 


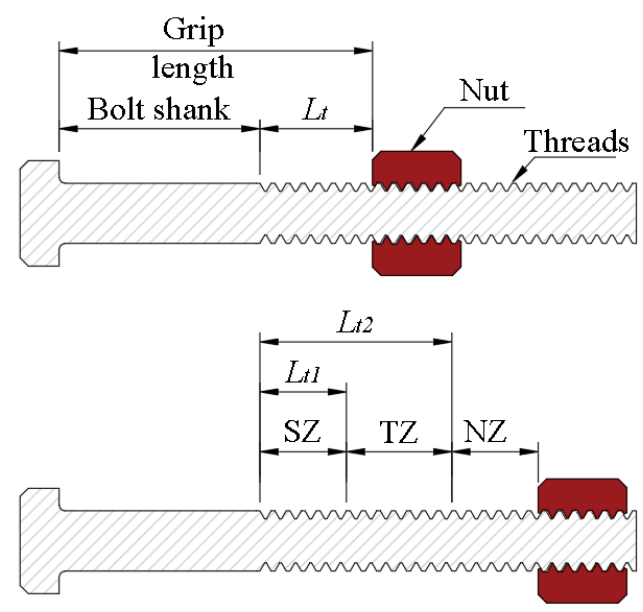

Figure 6: Critical nut locations.

Specimens were identified by a specific four field identifier as illustrated in Fig. 7. The first identifier represents the temperature, the second identifier represents the material type and the diameter of the bolt, the third identifier indicates the nut property class and the fourth identifier indicates the $L_{t}$ in terms of the thread pitch distance.

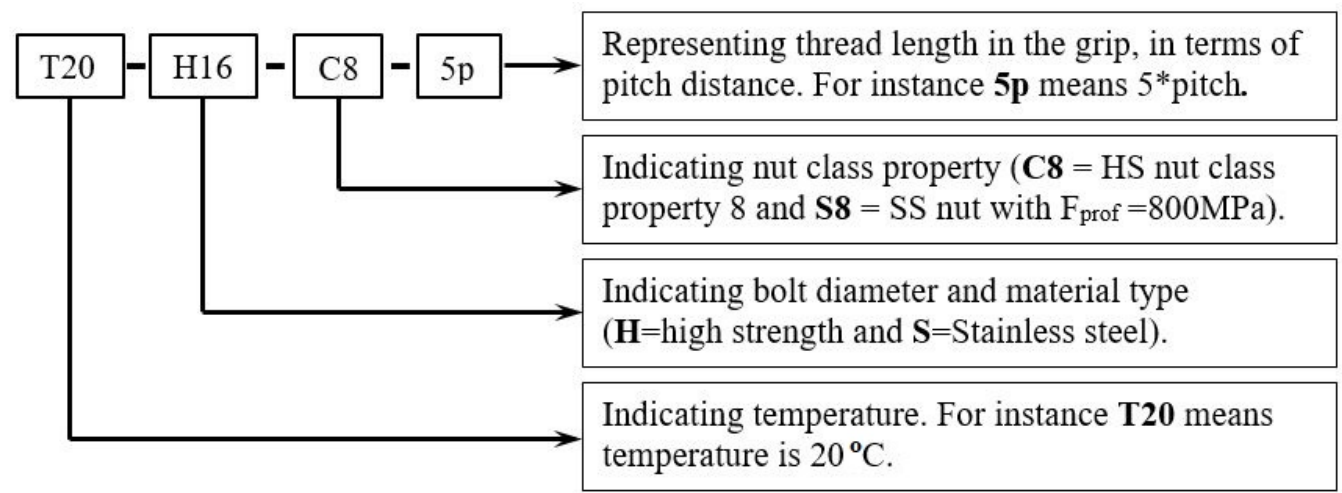

Figure 7: Specimen identifier.

\section{Ductility and failure mechanism of the bolt assemblies}

At elevated temperature, the catenary deformations of the beam transmit forces to the columns, placing significant ductility demands upon the bolt assemblies. The FE results 
shown in Fig. 8 compare the load-displacement response of the high strength and stainless steel bolt assemblies at $20^{\circ} \mathrm{C}$ and $600^{\circ} \mathrm{C}$. Two models were selected for each temperature based on the failure type, the first model failing by necking (dotted curves) and the second model failing by stripping (solid curves). Generally, stainless steel bolts recorded significantly higher ductility than the high strength bolts, exhibiting substantial elongation before failure. When the bolt assemblies failed in stripping, the high strength bolt experienced a severe reduction in ductility while the stainless steel bolt maintained a ductile response. This can be attributed to the differences in stripping failure mechanisms between high strength and stainless steel bolts. Stripping of high strength bolts result from the shear failure of the bolt threads without any flexural deformation; the threads of stainless steel bolts were severely deformed and stripping took place by sliding of the nut threads over the bolt threads (see Fig.9).

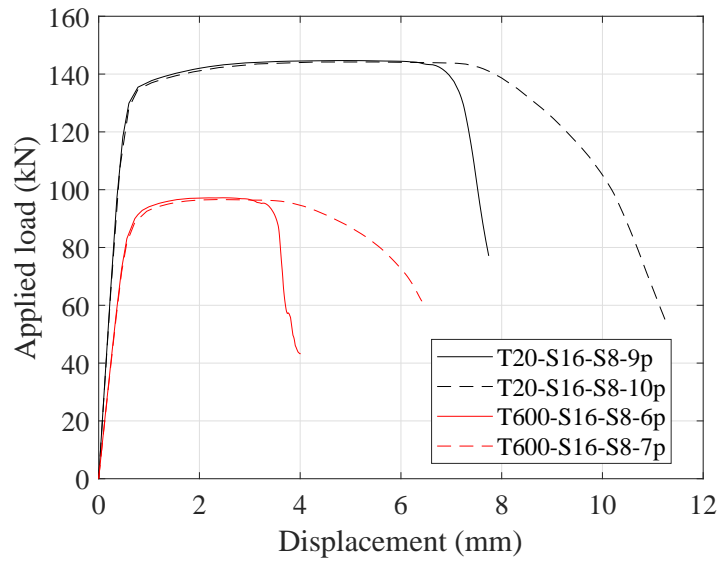

(a) Stainless steel bolt assemblies.

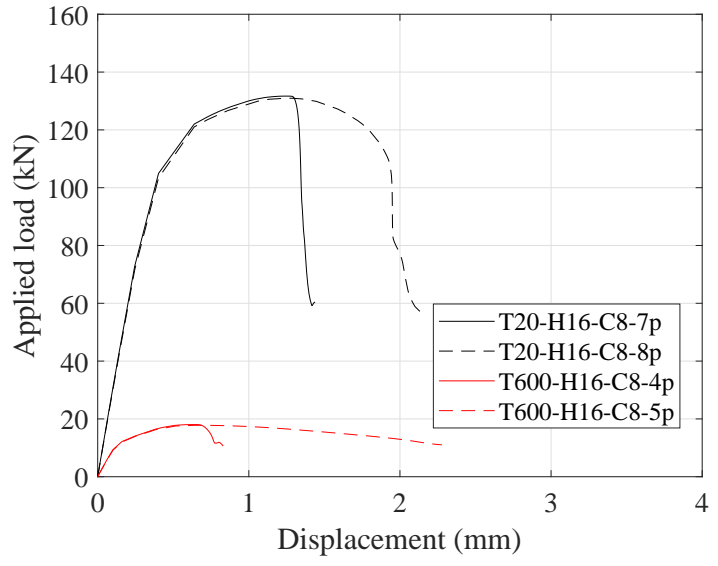

(b) High strength bolt assemblies.

Figure 8: Bolt ductility at elevated temperature considering different failure modes, necking failure (dashed line) and stripping failure (solid line).

The stripping failure was initiated when contact surfaces between the mating threads were reduced due to the lateral outward displacement of the nut (nut dilation) or lateral inward displacement of the bolt (bolt contraction) due to necking. Fig. 10 illustrates the nut dilation 


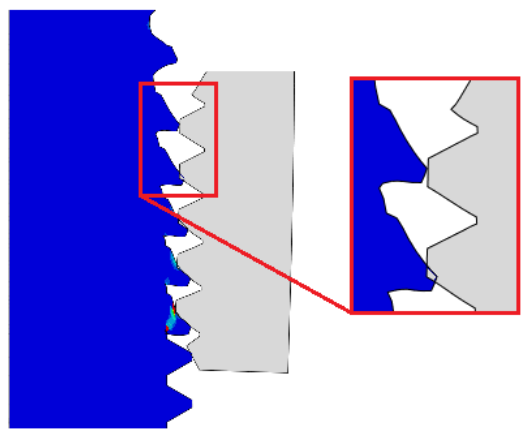

SS bolt assemblies

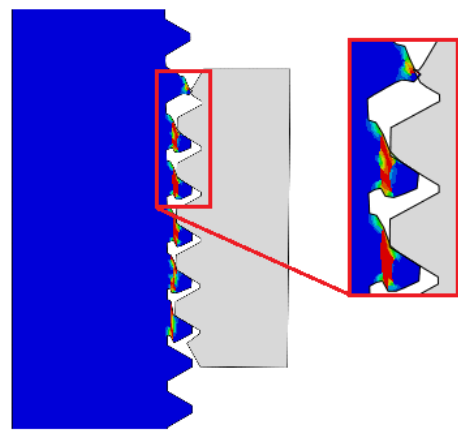

HS bolt assemblies

Figure 9: Comparison of stripping failure mechanism for high strength and stainless steel bolt assemblies.

and bolt contraction for both high strength and stainless steel bolt assemblies. It is clear that the stripping failure of the high strength bolt was mainly attributed to nut dilation and bolt contraction. For the stainless steel bolt, the reduction in the bolt area was much higher due to the more ductile response, resulting in a significant lateral contraction of the bolt. Fig. 11 shows the nut dilation and bolt contraction when different $L_{t}$ values were used. The nut dilation increased with the reduction in $L_{t}$. Despite the bolt thread contraction peaking at $L_{t}$ of five-times the pitch distance, the observed failure mode was necking. Ultimately, stripping occurred when the sum of the absolute lateral displacement of the nut and bolt peaked, corresponding to an $L_{t}$ value of four-times the pitch distance. 


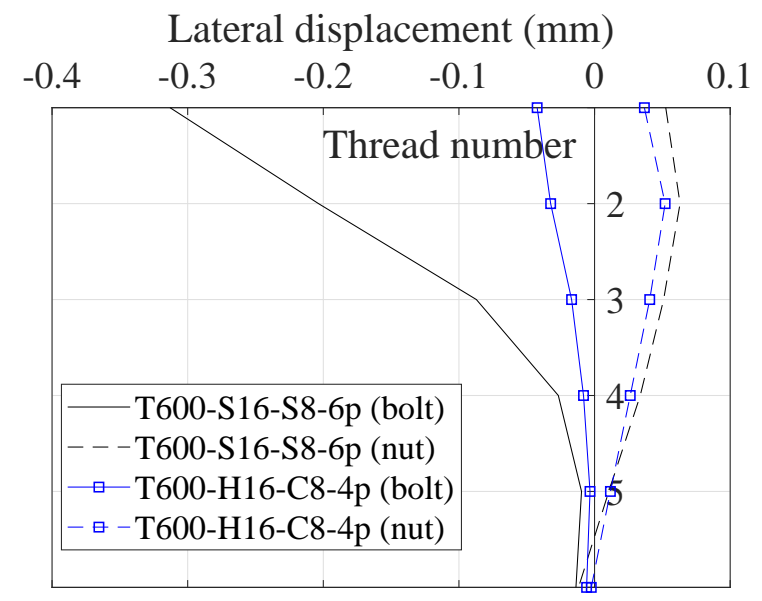

Figure 10: Lateral displacement of the bolt and the nut for stripping failure modes.

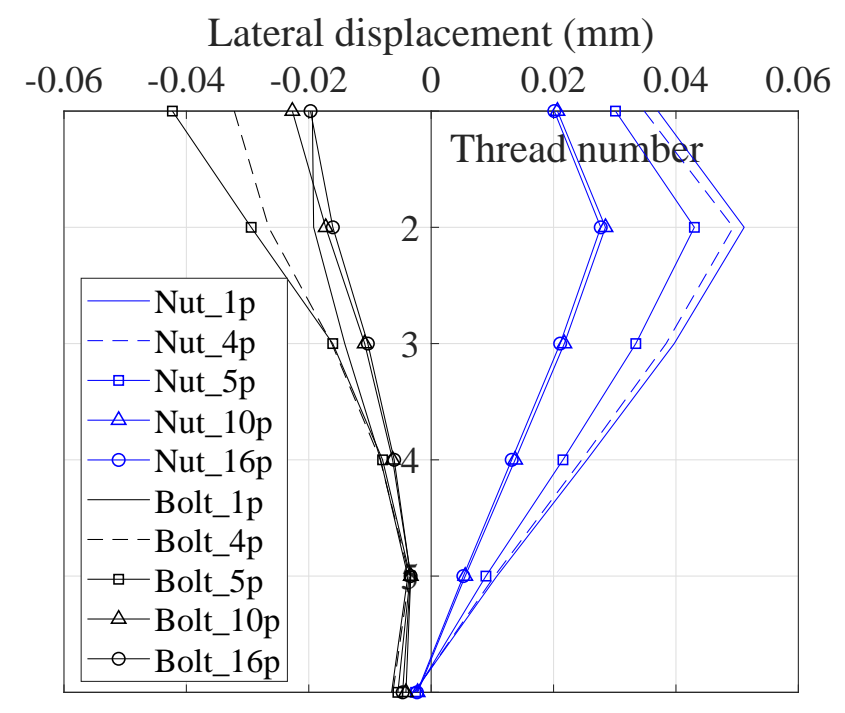

Figure 11: Effect of grip length on the nut dilation for T500-H16-C8-(see the legend).

\section{Failure mode with respect to the nut location}

Fig. 12 summarises the critical locations of high strength and stainless steel nuts with temperature. The two curves in each figure represent the boundaries between the three failure zones: stripping zone (SZ), transition zone (TZ) and necking zone (NZ) when different nut dimension deviations were used. It is clear that $L_{t 1}$ and $L_{t 2}$ depend on the nut dimension 
deviation and the temperature level. In the SZ, stripping failure occurred regardless of the nut dimension deviation. In the TZ, bounded between the solid and dotted curves, the stripping failure depended on the dimension deviation of the thread from the basic profile. The bolt failed by necking in the NZ, regardless of the nut dimensions when the nut was located away from the bolt shank with a distance following the solid curves. For example, stripping failure is avoided at $500^{\circ} \mathrm{C}$ when the nut is located away from the bolt shank with $L_{t}$ equal to or larger than 5 times the pitch distance $(=10 \mathrm{~mm})$ for the high strength M16 bolt and 7 times the pitch distance $(=14 \mathrm{~mm})$ for stainless steel M16 bolt. The required $L_{t}$ distance can be satisfied in practice by using a proper bolt length and diameter with appropriate plate thickness. Additionally, washers and shims can be inserted to achieve this distance.

The required $L_{t 2}$ reduced with temperature for high strength bolts while the value fluctuated between 6 and 10 times the pitch distance for the stainless steel bolts without a discernible pattern. Bolt stripping is essentially shear failure which is affected by the shear capacity of the threads. Both tensile and shear strength are reduced with temperature at different rates. The shear-to-tension ratios across the temperature range of the simulated bolts were calculated from the experimental data and illustrated in Fig. 13. For the high strength bolts, the shear-to-tension ratio increased with temperature, with a sudden rise beyond $400^{\circ} \mathrm{C}$. Accordingly, the stripping strength increased, which is reflected in Fig. 12 by reducing $L_{t 1}$ and $L_{t 2}$. Contrary to this, the shear-to-tension ratio of the stainless steel bolt remained almost unchanged with temperature, ranging between 0.58 and 0.72 . 

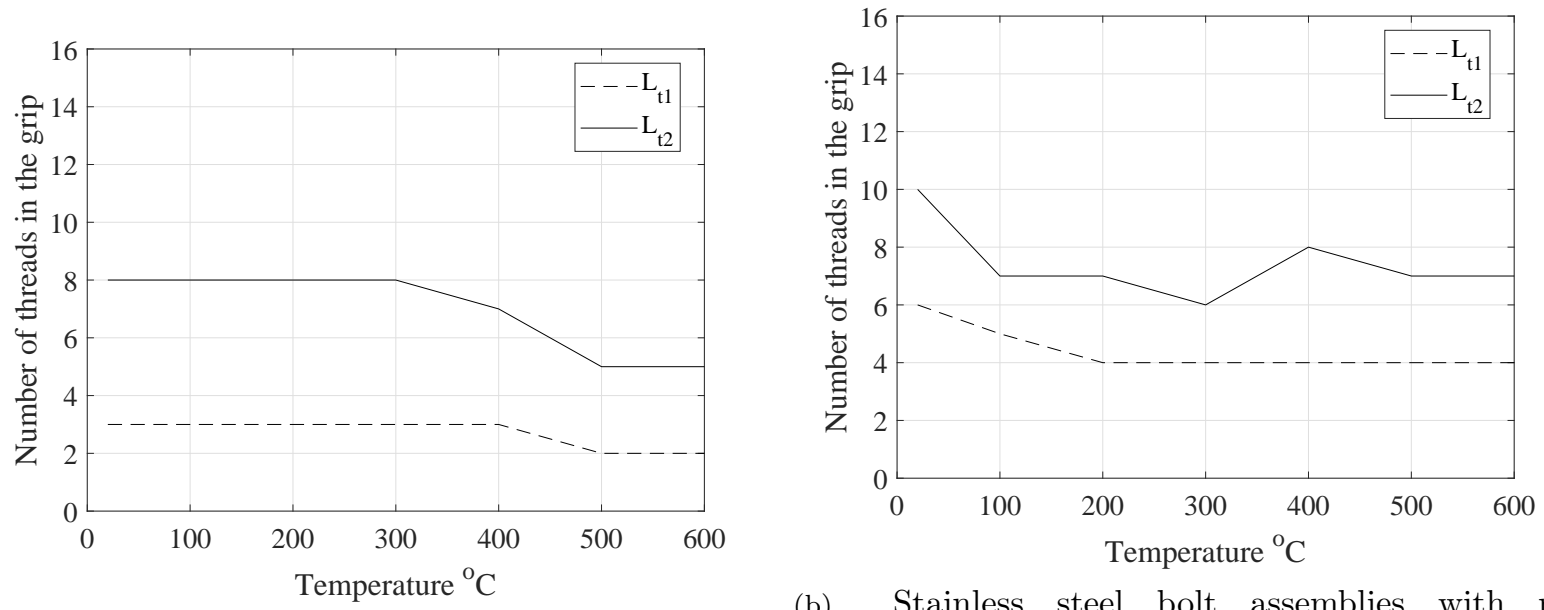

(b) Stainless steel bolt assemblies with nut (a) High strength bolt assemblies with nut class $8 . \mathrm{F}_{\text {prof }}=800 \mathrm{MPa}$.

Figure 12: Critical nut locations with temperature for high strength and stainless steel bolt assemblies.

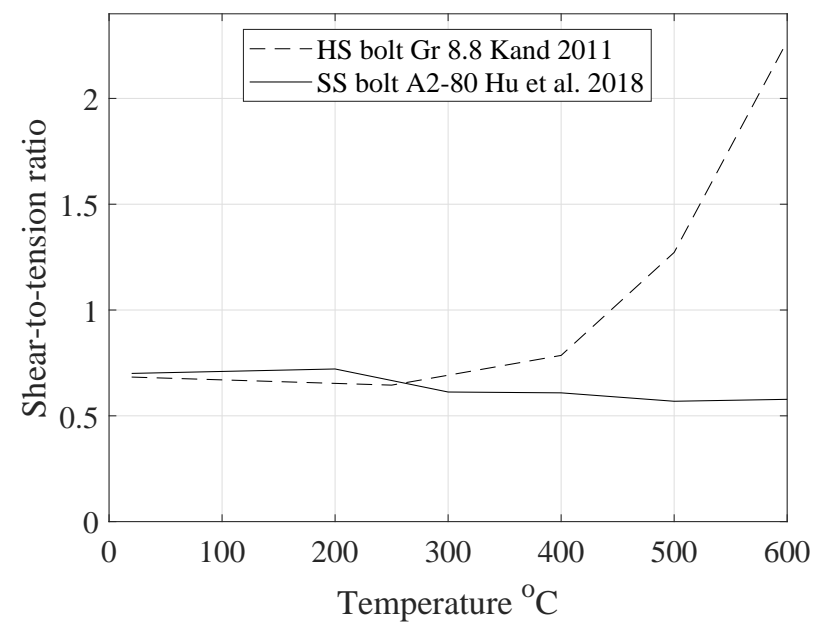

Figure 13: Shear-to-tension ratio as tested by Kand [23] for high strength bolts and Hu et al. [24] for stainless steel bolts.

\section{Effect of relative strength}

Fig. 14 compares $L_{t 2}$ with the relative strength between the mating threads (Rs), the ratio of the nut strength to the bolt strength. $L_{t 1}$ is neglected hereafter as it provides impractically small distances requiring very thin plates. It is clear that the $L_{t 2}$ distances reduced with the increase in the relative strength and that the $L_{t 2}$ distance of stainless steel bolt assemblies were higher than high strength bolt assemblies with the same relative strength. 
The missing data for stainless steel bolts when $\mathrm{Rs}=0.965$ indicates that stripping failure occurred throughout the full thread range of the bolt.

The relative strength of 0.79 , which is equivalent to the minimum Brinell hardness (HB) value recommended by BS EN ISO 898-2 [27], resulted in stripping failure across the full thread range of the bolt. Thus, a specific HB range for high strength class 8 nuts for fire applications should be included in the specifications to avoid premature failure of the bolt. Otherwise, it is recommended to select class 10 nuts when bolts of grade 8.8 are used. The FE results showed that a relative strength of 1.2 provided minimum $L_{t 2}$ distances and any further increase in the relative strength did not affect the $L_{t 2}$ distances. Similarly the $L_{t 2}$ distances for stainless steel bolt assemblies were not significantly affected by the increase in the relative strength beyond 1.096, however, the stainless steel bolt assembly is sensitive to the reduction in the relative strength as it requires larger $L_{t 2}$ distances. Adopting a nut with strength higher than the bolt strength reduces the nut dilation, which secures a larger thread shear area and a higher contact surface between the mating threads; accordingly higher resistance to stripping failure was achieved and ultimately the bolt failed in necking. 


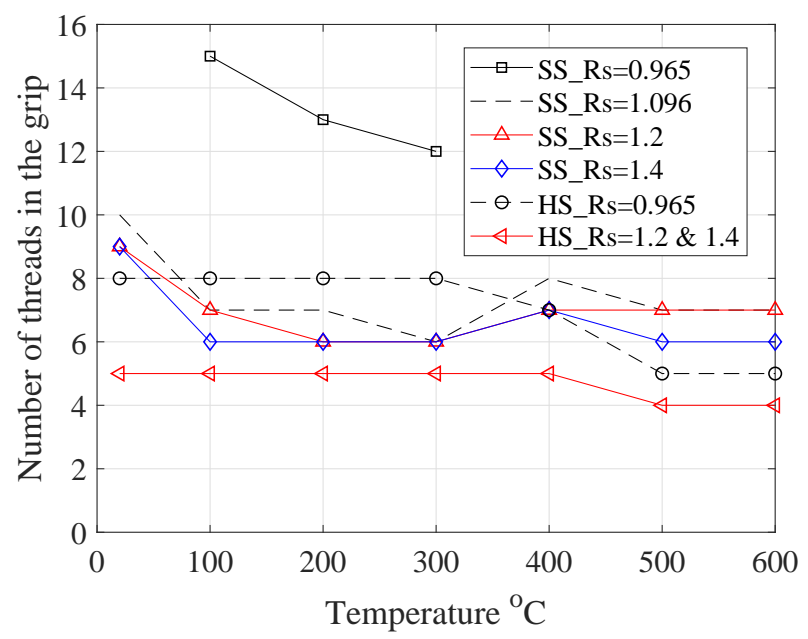

Figure 14: Effect of relative strength on $L_{t 2}$.

\section{Effect of friction}

The friction coefficient $\mu$ can vary with temperature for galvanised steel bolts and reaches its minimum value $(0.05)$ when the zinc melts at $425^{\circ} \mathrm{C}$. In contrast, a stainless steel bolt is an inherently corrosion resistant material that does not require any protective layer, thus it was assumed that $\mu$ value (0.2) between its mating thread remained constant across the considered temperature range $\left(20^{\circ} \mathrm{C}-600^{\circ} \mathrm{C}\right)$. Fig. 15 depicts the effect of $\mu$ on the NZ range for various relative strengths (Rs). As before, missing data corresponding to a specific temperature indicates that stripping failure occurred throughout the full thread range of the bolt. The reduction in $\mu$ allowed the nut to dilate more easily. Thus, lowering the stripping resistance and necessitating larger $L_{t 2}$. 


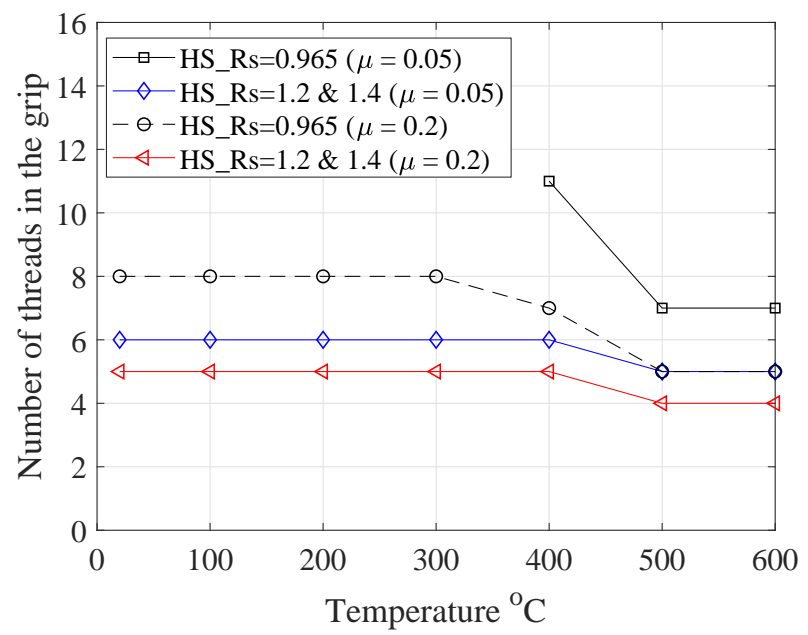

Figure 15: Effect of friction on the necking zone (NZ).

\section{Effect of bolt diameter}

Table 8 illustrates the critical locations of high strength and stainless steel nuts with temperature for an M20 bolt. By comparing the values of M20 and M16 bolts (as it is shown in Fig. 12), it is clear that the required $L_{t 1}$ and $L_{t 2}$ increases with the bolt diameter, indicating that the larger bolt diameter is more vulnerable to stripping failure attributing to the lower shear capacity of its threads comparing with its tensile capacity. Also, the effect of the nut dimension deviation was more detrimental for larger diameters, particularly for high strength bolts. Adopting the upper dimension deviation of high strength M20 nuts resulted in stripping failure for all locations except when the temperature was $600^{\circ} \mathrm{C}$, however, the $L_{t}$ distances were slightly increased for stainless steel types. The average dimension deviation was thus considered for the M20 bolt. With the reduction in dimension deviation from the basic profile, the likelihood of stripping failure can be reduced as it is shown in the table for the values corresponding to $L_{t 3}$. 
Table 8: Effect of bolt diameter on $L_{t}$ distances $(\mu=0.2)$, the values in the table are for the number of threads in the grip.

\begin{tabular}{|c|c|c|c|c|c|c|}
\hline \multirow{2}{*}{$\begin{array}{l}\text { Temp. } \\
{ }^{\circ} \mathrm{C}\end{array}$} & \multicolumn{3}{|c|}{ SS bolt Rs $=1.096$} & \multicolumn{3}{|c|}{ HS bolt $\mathrm{Rs}=0.965$} \\
\hline & $L_{t 1}$ & $L_{t 2}$ & $L_{t 3}{ }^{*}$ & $L_{t 1}$ & $L_{t 2}$ & $L_{t 3}{ }^{*}$ \\
\hline 20 & 6 & 13 & 7 & 4 & $x$ & 8 \\
\hline 100 & 5 & 9 & 7 & 4 & $x$ & 8 \\
\hline 200 & 6 & 13 & 11 & 4 & $x$ & 8 \\
\hline 300 & 4 & 8 & 7 & 4 & $x$ & 8 \\
\hline 400 & 5 & 10 & 8 & 4 & $x$ & 8 \\
\hline 500 & 5 & 10 & 8 & 3 & $x$ & 6 \\
\hline 600 & 5 & 10 & 7 & 3 & 10 & 6 \\
\hline \multicolumn{7}{|c|}{$\begin{array}{l}{ }^{*} L_{t 3} \text { has the same definition of } L_{t 2} \text { with the nut dimension deviation } \\
\text { changed from the upper value to the average value between the upper } \\
\text { and the lower deviations. } \\
x=\text { stripping occurred for all nut locations. } \\
\text { Rs = relative strength. }\end{array}$} \\
\hline
\end{tabular}

\section{Fully-threaded bolts}

Fully-threaded bolts were analysed with different nut dimension deviation and various temperatures. The analysis showed that the failure modes of fully-threaded and partiallythreaded bolts were identical when the number of threads in the grip are similar. In other words, the failure modes can be defined by the number of threads in the grip irrespective of the bolt type.

\section{Conclusions}

A comprehensive numerical study was carried out to investigate factors affecting the failure modes of bolt assemblies at elevated temperatures. Both stainless and high strength steel bolt assemblies were considered and their behaviour at ambient and elevated temperatures was compared. The FE model used in the parametric analysis was initially validated against experimental tests found in the literature. The material damage parameters for stainless and high strength steel at elevated temperature are presented. The FE simulation can accurately capture the key element failure modes of necking and stripping observed in the experimental 
tests. The paper discusses the major factors affecting the ductility and failure modes of bolt assemblies including (i) the number of threads in the grip $L_{t}$; (ii) the relative strength between the mating threads; (iii) the friction coefficient $\mu$ between the mating threads; (iv) the diameter of the bolt; and (v) the bolt type (partially- or fully- threaded).

Stripping failure was found to be controlled by the combined stiffness of both the nut and bolt rather than the individual components. When stripping took place, it deteriorated the ductility of the high strength bolts while stainless steel bolts continued to display a ductile response. At ambient temperature, stripping failure occurs at a certain length $L_{t}$. This length tends to reduce with the temperature for the high strength bolts while the value fluctuated without a discernible pattern for the stainless steel bolts examined here.

The increase in the relative strength between the mating threads resulted in reduction of $L_{t}$ for both bolt types. The minimum Brinell hardness (HB) value for grade 8 nuts suggested by BS EN 898-2 resulted in stripping failure across the full thread length of the bolt. Thus, further studies are required to define nut HB range for fire applications to avoid premature failure of the bolt. Otherwise, nuts of one property class higher can be used (i.e. nut property class 10 mating with bolt grade 8.8).

Larger bolt sizes are more vulnerable to thread stripping failure. For example, to avoid stripping failure for a high strength M20 bolt at $600^{\circ} \mathrm{C}$, the number of threads in the grip should be larger than 10 compared with 5 for an M16 bolt at the same temperature. This study suggested that the failure mode of partially- and fully-threaded bolt types is identical providing that the number of threads in the grip are similar. Therefore, the failure modes can be defined based on the number of threads in the grip, irrespective of the bolt type. 


\section{Acknowledgements}

This project is funded by a University of Manchester Dean's Award Scholarship, whose sponsorship is gratefully acknowledged. Dr. Jonathan Gosaye Fida Kaba is duly acknowledged.

\section{References}

[1] M. A. Shaheen, A. S. Foster, L. S. Cunningham, and S. Afshan, "Behaviour of stainless and high strength steel bolt assemblies at elevated temperatures - A review," Fire Safety Journal, vol. 113, p. 102975, may 2020.

[2] H. Yu, I. W. Burgess, J. B. Davison, and R. J. Plank, "Experimental and Numerical Investigations of the Behavior of Flush End Plate Connections at Elevated Temperatures," Journal of Structural Engineering, vol. 137, no. 1, pp. 80-87, 2011.

[3] S. Spyrou, J. B. Davison, I. W. Burgess, and R. J. Plank, "Experimental and analytical investigation of the tension zone components within a steel joint at elevated temperatures," Journal of Constructional Steel Research, vol. 60, no. 6, pp. 841-865, 2004.

[4] Y. C. Wang, X. H. Dai, and C. G. Bailey, "An experimental study of relative structural fire behaviour and robustness of different types of steel joint in restrained steel frames," Journal of Constructional Steel Research, vol. 67, no. 7, pp. 1149-1163, 2011.

[5] B. R. Kirby, "The Behaviour of High-strength Grade 8.8," Journal of Constructional Steel Research, vol. 33, pp. 3-38, 1995.

[6] Y. Hu, J. B. Davison, I. W. Burgess, and R. J. Plank, "Comparative study of the behaviour of BS 4190 and BS EN ISO 4014 bolts in fire," Proceedings of the 3rd International Conference on Steel and Composite Structures, ICSCSO7 - Steel and Composite Structures, pp. 587-592, 2007. 
[7] Y. Hu, L. Shen, S. Nie, B. Yang, and W. Sha, "FE simulation and experimental tests of high-strength structural bolts under tension," Journal of Constructional Steel Research, vol. 126, pp. 174-186, 2016.

[8] E. L. Grimsmo, A. Aalberg, M. Langseth, and A. H. Clausen, "Failure modes of bolt and nut assemblies under tensile loading," Journal of Constructional Steel Research, vol. 126, pp. 15-25, 2016.

[9] AISC 360-16, "Specification for Structural Steel Buildings ANSI/AISC 360-16," An American National Standard, 2016.

[10] CEN, "BS EN 1993-1-2:2005 - Eurocode 3: Design of Steel Structures - Part 1-2: General Rules - Structural Fire Design," Eurocode 3, 2005.

[11] E. M. Alexander, "Analysis and Design of Threaded Assemblies," SAE Technical Paper 770420, pp. 1838-1852, 1977.

[12] J. J. Chen and Y. S. Shih, "Study of the helical effect on the thread connection by three dimensional finite element analysis," Nuclear Engineering and Design, vol. 191, no. 2, pp. 109-116, 1999.

[13] J. Lange and F. González, "Behavior of High-Strength Grade 10.9 Bolts under Fire Conditions," Struct. Eng. Int., vol. 22, no. 4, pp. 470-475, 2012.

[14] BS EN ISO 898-1, "Mechanical properties of fasteners made of carbon steel and alloy steel Part 1: Bolts, screws and studs with specified property classes - Coarse thread and fine pitch thread," 2013.

[15] BSI, "BS EN ISO 3506-1:2009 - Mechanical Properties of Corrosion-Resistant Stainless Steel Fasteners - Part 1- Bolts, Screws and Studs," BSI, London, UK, 2009.

[16] ABAQUS, "Standard User's Manual," Hibbitt, Karsson and Sorensen, Inc, 2019. 
[17] BSI, "BS EN ISO 4014:2011 - Hexagon head bolts - Product grades A and B," BSI, London, UK, 2011.

[18] BSI, "BS EN ISO 4032:2012 - Hexagon regular nuts (style 1) - Product grades A and B," BSI, London, UK, 2012.

[19] Y. J. Sun and R. D. Liao, "The Effect of Helix on the Nonlinear Analysis of Threaded Connection," Advanced Materials Research, vol. 148-149, no. 1, pp. 1741-1744, 2010.

[20] BSI, "BS ISO 965-1:2013 - ISO general purpose metric screw threads - Tolerances Part 1: Principles and basic data," BSI, London, UK, 2013.

[21] ABAQUS, "Abaqus 6.19," Dassault Systèmes Simulia Corp., Providence, RI, USA, 2019.

[22] M. Pavlović, Z. Marković, M. Veljković, and D. Bucrossed D Signevac, "Bolted shear connectors vs. headed studs behaviour in push-out tests," Journal of Constructional Steel Research, vol. 88, pp. 134-149, 2013.

[23] S. S. Kand, Effect of Temperature on Thermal and Mechanical Properties of High Strength Steel A325 and A490 Bolts. PhD thesis, Michigan State University, 2011.

[24] Y. Hu, C. B. Yang, L. H. Teh, and Y. B. Yang, "Reduction factors for stainless steel bolts at elevated temperatures," Journal of Constructional Steel Research, vol. 148, pp. 198-205, 2018.

[25] V. Kodur, S. Kand, and Wasim Khali, "Effect of temperature on thermal and mechanical properties of high strength steel A325 and A490 bolts," Journal of Materials in Civil Engineering, vol. 24, no. June, pp. 765-774, 2012.

[26] M. Sarraj, The behaviour of steel fin plate connections in fire. PhD thesis, 2007. 
[27] ISO 898-2, Mechanical properties of fasteners made of carbon steel and alloy steel Part 2 : Nuts with specified property classes - Coarse thread and fine pitch thread. Switzerland: ISO, 2012.

[28] W. D. Callister and D. G. Rethwisch, Materials Science and Engineering. New York: John wiley \& sons, 2007.

[29] BSI, "BS EN ISO 3506-2 - Mechanical properties of corrosion-restistant stainless steel fasteners - Part 2: Nuts," BSI, London, UK, 2009.

[30] T. Fukuoka and M. Nomura, "Proposition of Helical Thread Modeling With Accurate Geometry and Finite Element Analysis," Journal of Pressure Vessel Technology, vol. 130, no. 1, p. 011204, 2008.

[31] R. Barrett, "Fastener design manual," NASA Reference Publication 1228, 1990.

[32] F. Wald, M. Chladná, D. Moore, A. Santiago, and T. Lennon, "The Temperature Distribution in a Full-Scale Steel Framed Builing Subject to a Natural Fire," Steel and Composite Structures, vol. 6, no. 2, p. 159, 2006.

[33] ASFP, Fire protection for structural steel in buildings. 2004. 